\title{
VITILIGO PONCTUE: A RARE CLINICAL ENTITY
}

\author{
K.S. Dhillon¹, Krati R Varshney²
}

HOW TO CITE THIS ARTICLE:

KS Dhillon, Krati R Varshney. "Vitiligo ponctue: a rare clinical entity". Journal of Evolution of Medical and Dental Sciences 2013; Vol2, Issue 37, September 16; Page: 7042-7046.

ABSTRACT: Vitiligo is an acquired pigmentary disorder of unknown etiology that is clinically characterized by the development of white macules related to the selective loss of melanocytes. Onset at an advanced age occurs but is unusual, and should raise concerns about associated diseases, such as thyroid dysfunction, rheumatoid arthritis, diabetes mellitus, and alopecia areata. The course of the disease is unpredictable and the response to treatment varies. We report a case of vitiligo ponctue, a very rare and unusual clinical presentation of vitiligo. A 32 yrs old male patient, unmarried, working as a teacher, reported to us with chief complaints of multiple white patches on the body of 3 months duration. Biopsy was done and histopathological examination revealed marked absence of melanocytes and melanin in the epidermis, which was consistent with the findings of vitiligo. Associated autoimmune diseases were looked for. Thyroid studies, antinuclear antibodies (ANA) and screening for other organ-specific autoantibodies, fasting blood glucose levels and complete blood count with indices for pernicious anemia were evaluated and were all within normal limits. We advised the patient to apply a sunscreen on regular basis. We treated him with topical corticosteroids and calcineurin inhibitors. Systemically, Zinc sulphate and Levamisole was given and our patient responded well.

KEY WORDS: Vitiligo, Thyroid Dysfunction, Anti nuclear antibodies

INTRODUCTION: Vitiligo is an acquired disorder of the skin and mucous membranes that is characterized by well circumscribed, depigmented macules and patches and that occurs secondary to selective destruction of melanocytes. ${ }^{1,2}$ It may appear at any age; cases have, been reported as early as 6 weeks after birth. ${ }^{1,3,4}$ Approximately $0.5 \%$ to $1 \%$ of the population is affected, and almost half present before 20 years of age. Its prevalence appears to be equal between men and women, 1, 5 and there is no difference in rates of occurrence according to skin type or race. Vitiligo can be a psychologically devastating disease, especially in darker skinned individuals, in whom it is more easily noticeable. It appears to be transmitted genetically in a polygenic/multifactorial manner. The actual pathogenesis is under debate and has been attributed to autoimmune (AI) causes, oxidative stress, and/or sympathetic neurogenic disturbance. ${ }^{6}$ Vitiligo can be divided into two major classes: non segmental (NSV), which is more common, and segmental (SV). The Vitiligo European Task Force (VETF) defines NSV as "an acquired chronic pigmentation disorder characterized by white patches, often symmetrical, which usually increase in size with time, corresponding to a substantial loss of functioning epidermal and sometimes hair follicle melanocytes."7 SV occurs in a unilateral distribution that may totally or partially match a dermatome. ${ }^{7}$ Vitiligo lesions may itch and have a propensity to sunburn. The Koebner phenomenon is common. ${ }^{6}$ Vitiligo is a chronic persistent disorder8; spontaneous repigmentation is uncommon and occurs in a perifollicular pattern. ${ }^{9}$ Many patients are poorly educated about their illness. Firooz et al revealed, 51.3\% of patients believed that their vitiligo was caused by poor medical care, 30\% thought personal behavior played a role, $25 \%$ diet, $21.3 \%$ state of mind, and $20 \%$ blamed pollution. ${ }^{10}$ Vitiligo is divided into three types: 
localized, generalized, and universal.11, 12 Localized vitiligo is further subtyped into focal, segmental (dermatomal or Blaschko-linear;), and mucosal. ${ }^{8}$ Generalized vitiligo may be acrofacial, vulgaris, or mixed. Universal vitiligo involves more than $80 \%$ of the skin. Generalized vitiligo is the most common type, and vulgaris is the most common subtype. The sites of predilection for vitiligo vulgaris are the fingers and wrists, axillae and groin, and body orifices, such as the mouth, eyes, and genitals. 8,13

Vitiligo ponctue is rare; discrete, confetti-like amelanotic macules occur on normal or hyperpigmented skin. ${ }^{14}$

CASE REPORT: 32 yrs old male patient, unmarried, working as a teacher, reported to us with chief complaints of multiple white patches on the body of 3 months duration. Patient first noticed a solitary reddish white patch on central part of upper chest. Within a week of this manifestation, relatives of the patient noticed multiple small white patches scattered over the back. This was followed by development of similar white patches on his chest, abdomen, around the waist and both axillae. Later, patient also noticed a white patch on his left hand. The patches were not associated with any pain or itching. Patient denied suffering from any chronic ailment in the past. Patient had two episodes of Jaundice at age of 6 years and then at 25 yrs of age. No family history of vitiligo vulgaris was elicited. He was a tobacco chewer for last 3 years. Occasionally, smokes cigarette and consumes alcohol. Patient is a vegetarian. General physical examination revealed patient was of average built and well nourished. Vitals were normal. Systemic Examination was unremarkable.

Dermatological Examination: Revealed multiple scattered small confetti like depigmented macules with well defined borders on normal skin, varying in size from $2-3 \mathrm{~mm}$ to $0.5-1 \mathrm{~cm}$ (Fig. 1, 2) over the supra-scapular region, the scapulae, axillae, lower back along the waist and left hand. Depigmented macules were also seen on chest (Fig. 3) with poliosis (Fig. 4). Kobnerization was present around waist (Fig. 5). No scaling or loss of hair on patches. Nails \& mucous membrane were normal.

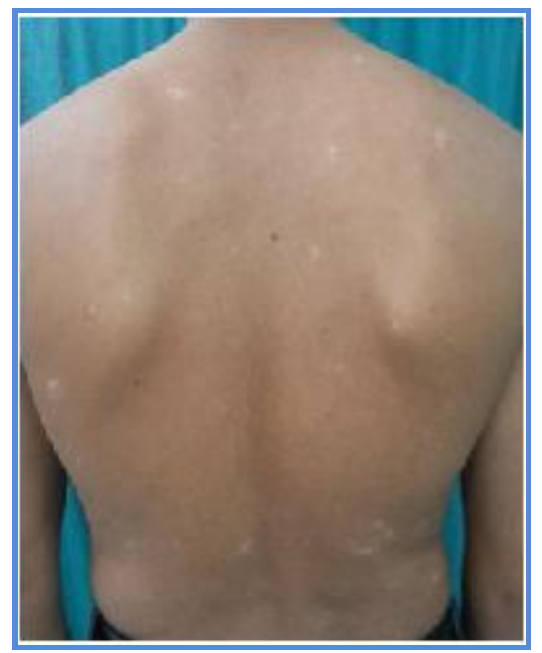

Fig. 1 (Hypopigmented

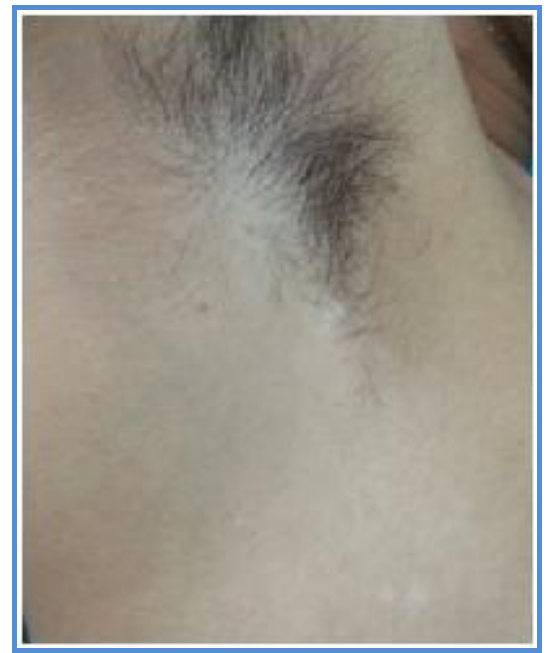

Fig. 2 (Invovement of axilla) 


\section{CASE REPORT}

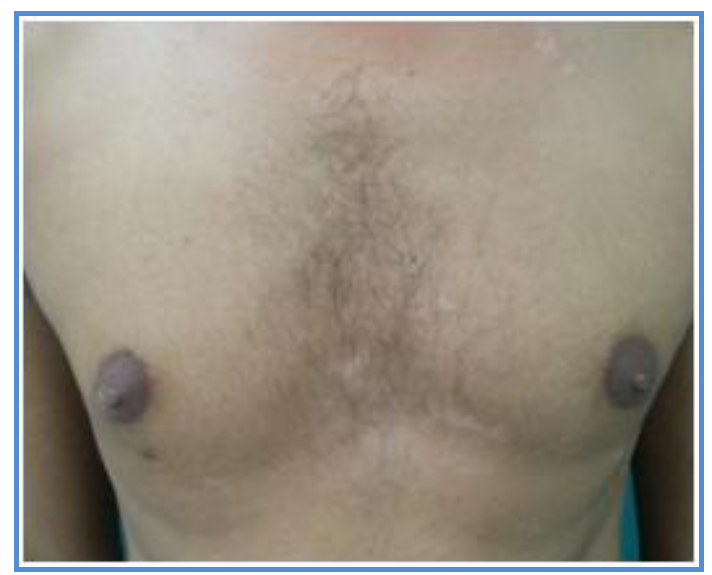

Fig. 3 (Lesions on Chest)

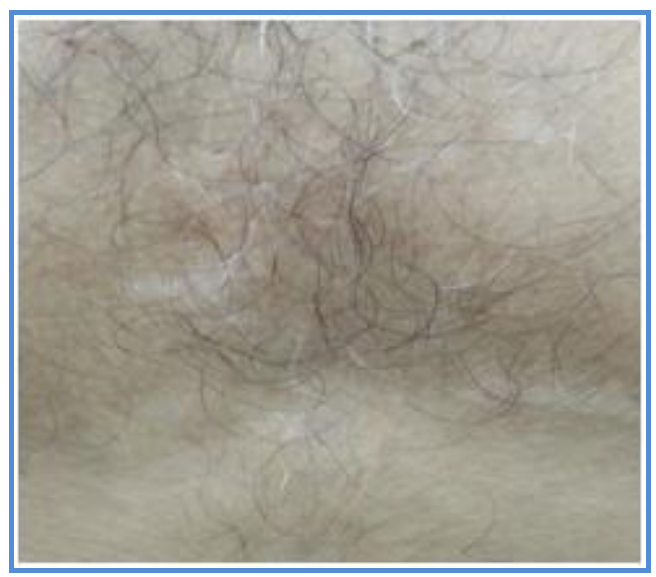

Fig.4 (Poliosis over lesions on chest)

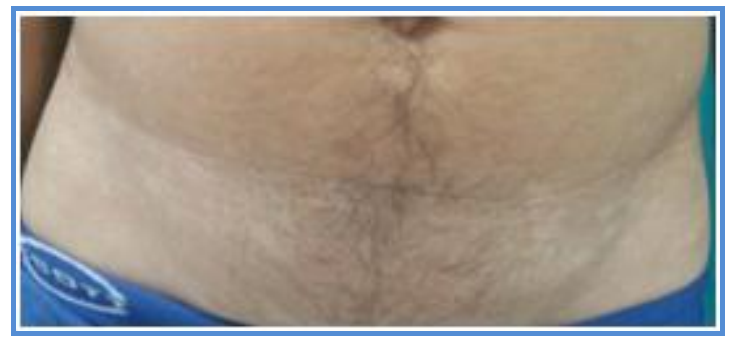

Fig. 5 (Koebnerization present over waist)

Specific investigations: Biopsy was done and histopathological examination revealed marked absence of melanocytes and melanin in the epidermis, which was consistent with the findings of vitiligo. Associated autoimmune diseases were looked for. Thyroid studies, antinuclear antibodies (ANA) and screening for other organ-specific autoantibodies, fasting blood glucose levels and complete blood count with indices for pernicious anemia were evaluated and were all within normal limits.

Treatment: We advised the patient to apply a sunscreen on regular basis. We treated him with topical corticosteroids and calcineurin inhibitors. Systemically, Zinc sulphate and Levamisole was given and our patient responded well.

DISCUSSION: We are reporting this case to highlight this rare clinical variant of vitiligo. To the best of our knowledge, this is the first case which came to our department .Based on our clinical experience; we are convinced that the prevalence of vitiligo ponctue is often under-reported and might be a crucial observation in at least a subgroup of patients with vitiligo.

This case report will help in increasing the awareness of this unusual entity since many of these cases may be coming under the ambit of post-inflammatory hypopigmentation. It will also bring into focus the various clinical presentations of vitiligo, which is of paramount importance to know since each clinical variant responds differently to treatment and has a unique prognosis. Vitiligo has various clinical presentations. Knowing and understanding these characteristics will 


\section{CASE REPORT}

immensely help in differentiating vitiligo from other hypopigmentary disorders, in effective planning of the treatment and to predict the prognosis to some extent.

CONCLUSION: Vitiligo is inherited in a non-mendelian, multifactorial, and polygenic pattern, with incomplete penetrance. Although vitiligo does not produce direct physical impairment, it poses a significant psychosocial burden, and quality of life improvement should be the most important outcome measure in future clinical trials.

ACKNOWLEDGMENT: The authors gratefully acknowledge the support of associated departments for the study.

\section{REFERENCES:}

1. Kyriakis KP, Palamaras I, Tsele E, Michailides C, Terzoudi S. Case detection rates of vitiligo by gender and age. Int J Dermatol 2009; 48:328-9.

2. Zhang Z, Xu SX, Zhang FY, Yin XY, Yang S, Xiao FL, et al. The analysis of genetics and associated autoimmune diseases in Chinese vitiligo patients. Arch Dermatol Res 2009; 301:167-73.

3. Porter JR, Beuf AH. Racial variation in reaction to physical stigma: a study of degree of disturbance by vitiligo among black and white patients. J Health Soc Behav 1991; 32: 192204.

4. Nanda A, Kaur S, Bhakoo ON, Dhall K. Survey of cutaneous lesions in Indian newborns. Pediatr Dermatol 1989; 6:39-42.

5. Tamer E, Ilhan MN, Polat M, Lenk N, Alli N. Prevalence of skin diseases among pediatric patients in Turkey. J Dermatol 2008; 35:413-8.

6. Taieb A, Picardo M. Clinical practice. Vitiligo. N Engl J Med2009; 360:160-9.

7. Taieb A, Picardo M. The definition and assessment of vitiligo: a consensus report of the Vitiligo European Task Force. Pigment Cell Res 2007; 20:27-35.

8. Gawkrodger DJ, Ormerod AD, Shaw L, Mauri-Sole I, Whitton ME, Watts MJ, et al. Guideline for the diagnosis and management of vitiligo. Br J Dermatol 2008; 159:1051-76.

9. Castanet J, Ortonne JP. Pathophysiology of vitiligo. Clin Dermatol 1997; 15:845-51.

10. Firooz A, Bouzari N, Fallah N, Ghazisaidi B, Firoozabadi MR, Dowlati Y. What patients with vitiligo believe about their condition. Int J Dermatol 2004; 43:811-4.

11. Shajil EM, Chatterjee S, Agrawal D, Bagchi T, Begum R. Vitiligo: pathomechanism and genetic polymorphism of susceptible genes. Indian J Exp Biol 2006; 44:526-39.

12. Nordlund JJ, Lerner AB. Vitiligo. It is important. Arch Dermatol 1982; 118:5-8.

13. Arycan 0, Koc K, Ersoy L. Clinical characteristics in 113 Turkish vitiligo patients. Acta Dermatovenerol Alp Panonica Adriat 2008; 17:129-32.

14. Ortonne JP. Vitiligo and other disorders of hypopigmentation. In: Bolognia J, Jorizzo J, Rapini R, editors. Dermatology. Philadelphia: Mosby Elsevier; 2008. p. 928. 


\section{AUTHORS:}

1. K.S. Dhillon

2. Krati R. Varshney

\section{PARTICULARS OF CONTRIBUTORS:}

1. Professor, Department of Dermatology, Era's Lucknow Medical College and Hospital, Lucknow, Uttar Pradesh, India.

2. Junior Resident, Department of Microbiology, Era's Lucknow Medical College and Hospital, Lucknow, Uttar Pradesh, India.

\section{NAME ADDRESS EMAIL ID OF THE CORRESPONDING AUTHOR:}

Dr. Krati R Varshney,

A-17, New Girls Hostel,

Era's Lucknow Medical College and Hospital, Sarfarazganj, Hardoi Road, Lucknow.

Email - krativarshney2001@yahoo.co.in

Date of Submission: 01/09/2013.

Date of Peer Review: 02/09/2013.

Date of Acceptance: 06/09/2013.

Date of Publishing: 10/09/2013 